\title{
Investigation of Influence of Compensator Element on the Structure and Properties of the Alloy AK12
}

\author{
Tatiana A. Bogdanova ${ }^{a}$, \\ Nikolay N. Dovzhenko ${ }^{\mathrm{b}}$, Galina A. Merkulovab, \\ Tatiana R. Gilmanshina*b, Maria V. Vaag ${ }^{\mathrm{a}}$, \\ Natalia V. Grudinina ${ }^{b}$ and Farid R. Latypov \\ ${ }^{a} K \& K$ ltd \\ 3 Berezina, Krasnoyarsk, 660020, Russia \\ ${ }^{b}$ Siberian Federal University \\ 79 Svobodny, Krasnoyarsk, 660041, Russia \\ ${ }^{c}$ Ufa State Aviation Technical University \\ 12 Karl Marks, Ufa, 450000, Russia
}

Received 03.03.2016, received in revised form 26.05.2016, accepted 04.07.2016

Possibility of using of aluminum A7 instead of A8 to reduce the cost automobile wheel discs, made from alloy AK12 by casting under low pressure is studied. The microstructure and properties of six experimental alloys are investigated. It is found that use of primary aluminum A7 instead of A8 is possible at insertion of a compensator element-manganese in an amount of not more than $0.20-0.25 \mathrm{wt} \%$. at the content of iron is not more than 0.20-0.25 wt. \%, that is ratio Fe: Mn has to be equal 1: 1. The mechanical properties demanded GOST 50511-93 are received.

Keywords: silumin, structure, mechanical properties, automobile wheel discs.

Citation: Bogdanova T.A., Dovzhenko N.N., Merkulova G.A., Gilmanshina T.R., Vaag M.V., Grudinina N.V. Latypov F.R. Investigation of influence of compensator element on the structure and properties of the alloy AK12, J. Sib. Fed. Univ. Eng. technol., 2016, 9(5), 750-757. DOI: 10.17516/1999-494X-2016-9-5-750-757.

(C) Siberian Federal University. All rights reserved

* Corresponding author E-mail address: gtr1977@mail.ru 


\title{
Исследование влияния элемента-компенсатора на структуру и свойства сплава АК12
}

\author{
Т.А. Богданова ${ }^{a}$, Н.Н. Довженко \\ Г.А. Меркулова ${ }^{\sigma}$, Т.Р. Гильманшина ${ }^{\sigma}$, \\ М.В. Вааг ${ }^{\mathrm{a}}$, Н.В. Грудинина ${ }^{\tilde{\sigma}}$, Ф.Р. Латыпов ${ }^{\text {в }}$ \\ ${ }^{a} \mathrm{OOO} \ll K u K »$ \\ Россия, 660020, Красноярск, ул. Березина, 3 \\ ${ }^{6}$ Сибирский федеральный университет \\ Россия, 660041, Красноярск, пр. Свободный, 79 \\ ${ }^{8}$ Уфимский государственный \\ авиачионный технический университет \\ Россия, 450000, Уфа, ул. К. Маркса, 12
}

Изучена возможность использования алюминия марки А7 вместо А8 для удешевления дисков автомобильных колес, изготавливаемых из сплава АК12 литьем под низким давлением. Исследована микроструктура и свойства шести опытных сплавов. Установлено, что использование первичного алюминия $A 7$ вместо А8 возможно при введении элементакомпенсатора - марганца - в количестве не более 0,20-0,25\% масс. при содержании железа не более 0,20-0,25\% масс., т.е. соотночение Fе : Мп должно быть равно $1: 1$. Получень требуемые ГОСТ 50511-93 механические свойства.

Ключевые слова: силумин, структура, механические свойства, диски автомобильных колес.

\section{Введение}

Диски автомобильных колес изготавливают из различных материалов: из стали, титановых, магниевых и алюминиевых сплавов $[1,2]$. Для получения силумина марки АК12 в России традиционно используют первичный алюминий марки А8, А85. С целью удешевления было предложено применять алюминий марки A7, содержащий больше железа. Для нейтрализации вредного влияния железа вводят элементы-компенсаторы: марганец, бериллий или молибден.

Известно, что элементы-компенсаторы подавляют образование иглообразной $\beta$-фазы (Al, $\mathrm{Si}, \mathrm{Fe})$. При введении компенсаторов $\beta$-фаза кристаллизуется в форме глобулярных включений или включений, получивших название «китайский шрифт» $[3,4]$. При использовании марганца в сплавах формируется соединение $(\mathrm{Fe}, \mathrm{Mn})_{3} \mathrm{Si}_{2} \mathrm{Al}_{15}$, которое первично кристаллизуется из расплава в виде компактных ограненных кристаллов, что способствует повышению пластичности, если эти кристаллы достаточно мелкие [5, 6].

В настоящей работе для уменьшения вредного влияния железа на свойства сплава АК12 выбран марганец.

Цель работы: изучить микроструктуру и свойства опытных сплавов на основе марки АК12, содержащих разное количество железа и марганца, и установить оптимальное соотношение $\mathrm{Fe}: \mathrm{Mn}$ в сплаве, обеспечивающее требуемые ГОСТ Р 501511-93 механические свойства и для снижения себестоимости дисков автомобильных колес. 


\section{Методика проведения исследований}

Работа выполнена на ООО «КиК» и в ИЦМиМ СФУ.

Приготовлено шесть опытных сплавов, в которых количество железа изменяли от 0, 15 до 0, 32 масс. \% при различном соотношении железа и марганца: соотношение $\mathrm{Fe}: \mathrm{Mn}$, paвное $1: 0$ (сплав № 1 выплавлен на алюминии марки А85); $1: 0,5 ; 1: 0,7 ; 1: 1$. Сплавы № 2-6 выплавляли на алюминии марки A7. Для получения сплавов системы Al-Si с содержанием железа до 0,15 \% применяли шихтовые материалы: первичный алюминий марки А85 (ГОСТ 11069-2001). Брали кремний кристаллический марки Кр00 (ГОСТ 2169-69). Сплавы с содержанием железа от 0,15 до 0,325 \% получали из первичного алюминия марок А7 и А7э (ГОСТ 11069-2001). Использовали кремний кристаллический марки Кр00 (ГОСТ 2169-69) и лигатуру AlMn20(B) (ГОСТ 53777-2010).

Приготовление расплава проводили в индукционной печи ИАТ-2,5 на плавильном участке ООО «КиК» по заводской технологии. Химический состав сплавов приведен в табл. 1 .

Изучение микроструктуры опытных сплавов и готовых изделий - дисков автомобильных колес, изготовленных на ООО «КиК» литьем под низким давлением, - проводили на микрошлифах с помощью оптических микроскопов OLIMPUS GX 51 и Axio Observer при увеличении до $\times 1000$.

Механические свойства определяли с использованием разрывной машины WDW-20 (ГОСТ 1497-84) и твердомера ТБ-5004 (ГОСТ 9012-59).

Определение сопротивления колеса удару под углом $13^{\circ}$ проводили на испытательном стенде SAMSUN (ГОСТ Р 50511-93).

\section{Результаты исследований и их обсуждение}

В обсуждении полученных результатов принял участие Ф.Р. Латыпов, канд. техн. наук, доцент УГАТУ, г. Уфа.

Результаты исследований микроструктуры образцов из сплавов № 1 - 6 системы Al-Si c различным соотношением железа и марганца приведены на рис. 1, 2 .

Исследования микроструктуры сплавов № 1-3 показали, что структура сплава без дополнительного легирования марганцем состоит из модифицированной эвтектики и грубых игл $\beta$-фазы стехиометрического состава $\mathrm{Al}_{5} \mathrm{FeSi}$ (рис. 1a).

Таблица 1. Химический состав опытных сплавов ${ }^{*}, \%$ масс.

\begin{tabular}{|c|c|c|c|c|c|}
\hline \multirow{2}{*}{ Номер сплава } & \multirow{2}{*}{$\begin{array}{c}\text { Марка } \\
\text { первичного } \\
\text { алюминия }\end{array}$} & \multirow{2}{*}{$\begin{array}{c}\text { Соотношение } \\
\mathrm{Fe}: \mathrm{Mn}\end{array}$} & \multicolumn{3}{|c|}{ Содержание элемента, масс. \% } \\
\hline & & & $\mathrm{Si}$ & $\mathrm{Fe}$ & $\mathrm{Mn}$ \\
\hline 1 & A8, A85 & $1: 0$ & 11,4 & 0,15 & 0,01 \\
\hline 2 & \multirow{5}{*}{ A7 } & $1: 0,5$ & 11,2 & 0,19 & 0,09 \\
\hline 3 & & $1: 1$ & 11,3 & 0,21 & 0,20 \\
\hline 4 & & $1: 0,5$ & 11,3 & 0,30 & 0,17 \\
\hline 5 & & $1: 0,7$ & 11,3 & 0,25 & 0,17 \\
\hline 6 & & $1: 1$ & 11,3 & 0,32 & 0,31 \\
\hline
\end{tabular}

* Алюминий - основа сплавов. 
При соотношении $\mathrm{Fe}: \mathrm{Mn}$, равном $1: 0,5$, в структуре наблюдаются микрообъемы с грубыми включениями $\beta$-фазы, а также обнаруживается присутствие $\mathrm{Al}_{15}(\mathrm{FeMn})_{3} \mathrm{Si}_{2}$ в виде китайского иероглифа - $\alpha$-фаза (рис. 16 ).

Дальнейшее увеличение содержания марганца в сплаве АК12 и доведение соотношения $\mathrm{Fe}: \mathrm{Mn}$ до $1: 1$ вызывает полное исчезновение игольчатой модификации железистой фазы и образование более компактной $\alpha$-фазы по всему сечению шлифа (рис. 18). Структура, получившая название «китайский шрифт» [3], свидетельствует о том, что введение элемента-компенсатора в необходимом количестве подавляет образование иглообразной $\beta$-фазы.

Структура сплавов № 4 - 6, содержащих повышенное количество железа (табл. 1) при различном соотношении $\mathrm{Fe}: \mathrm{Mn}$, показана на рис. 2.

В исследуемых образцах при увеличении в 100 раз отчетливо видна микроструктура $\alpha$ твердого раствора и игольчатой эвтектики $(\alpha+S i)$. В сплаве № 4 и 6 наблюдается увеличение размера игл эвтектики, что можно объяснить большим содержанием железа (более 0,3 \%). В сплаве № 5 содержится меньшее количество железа (0,257 \%), поэтому его структура более дисперсная по сравнению со сплавами № 4 и 6 . Анализируя рис. 2, можно сделать вывод, что в исследуемый сплав (АК12) не нужно вводить более $0,3 \%$ железа.

Исследованы механические свойства образцов из опытных сплавов № 1-3 (рис. 3), а также дисков автомобильных колес из сплавов № 2, 3 в трех зонах (рис. 4).
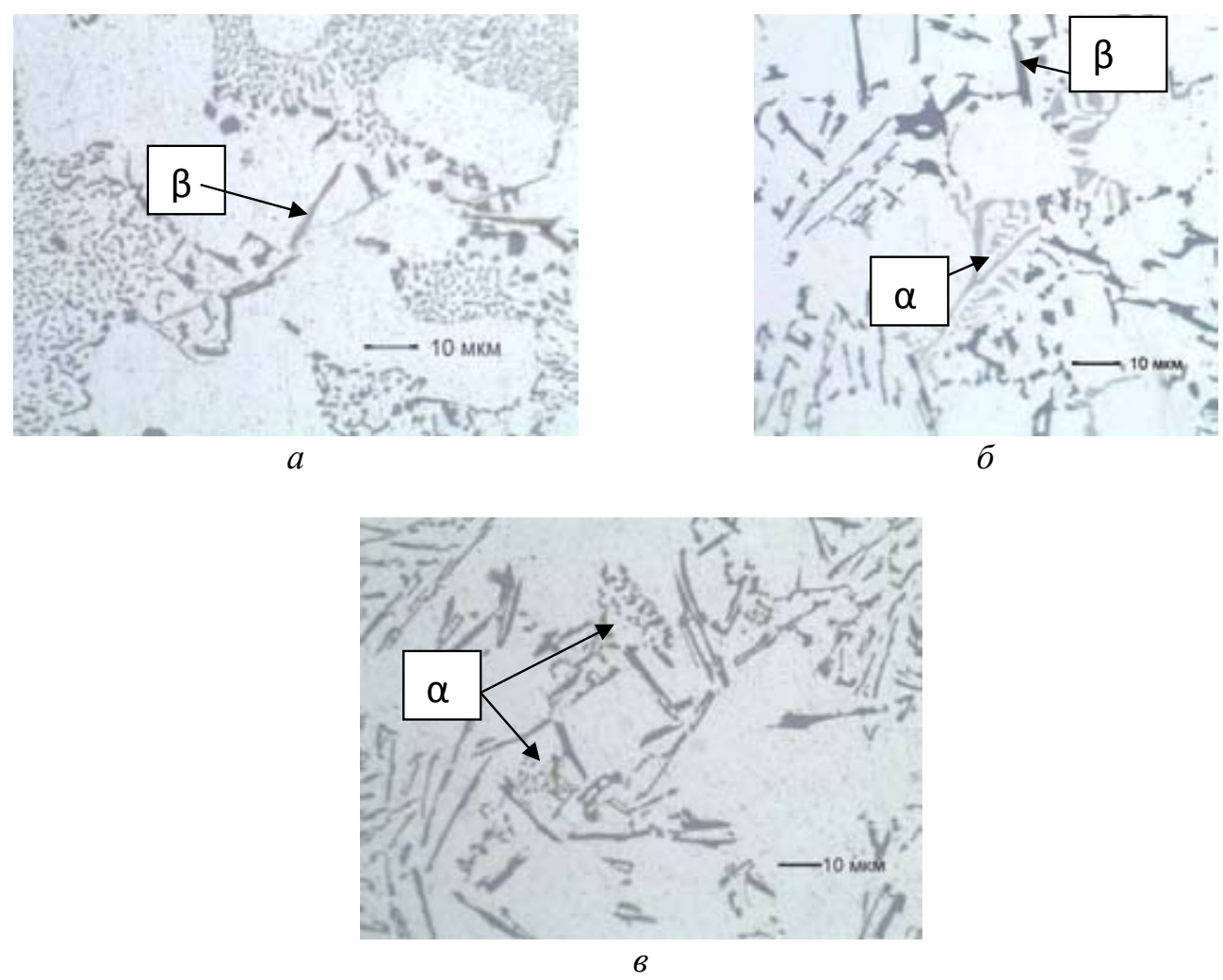

Рис. 1. Микроструктура алюминиевого сплава, полученного при различном соотношении $\mathrm{Fe}: \mathrm{Mn}$ : a $-1: 0$ (сплав № 1); б - $1: 0,5$ (сплав № 2); в - $1: 1$ (сплав № 3) 


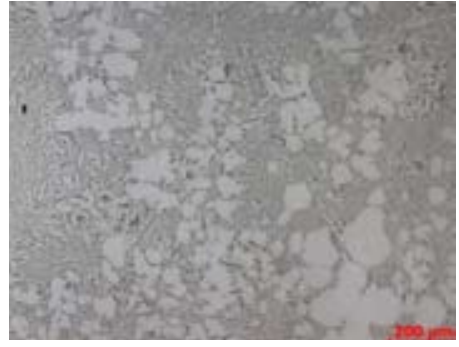

сплав 4

a

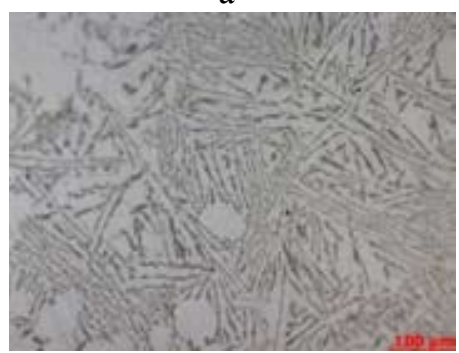

сплав 4

$\Gamma$

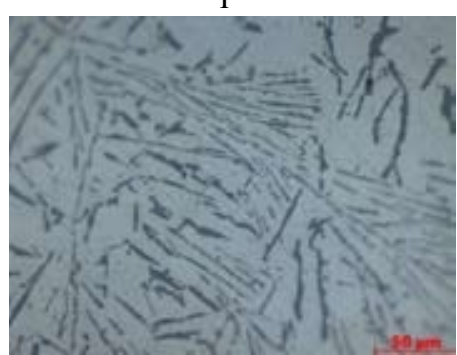

сплав 4

ж

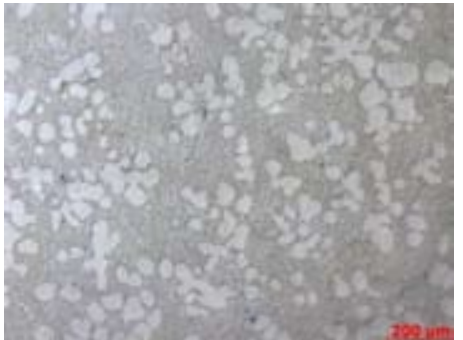

сплав 5

6

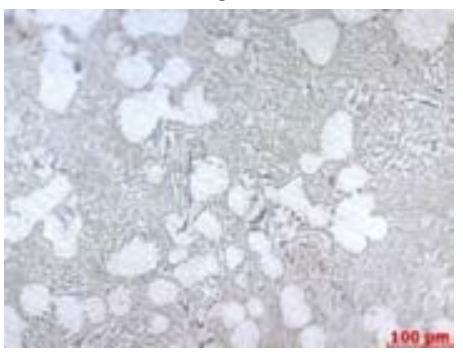

сплав 5

Д

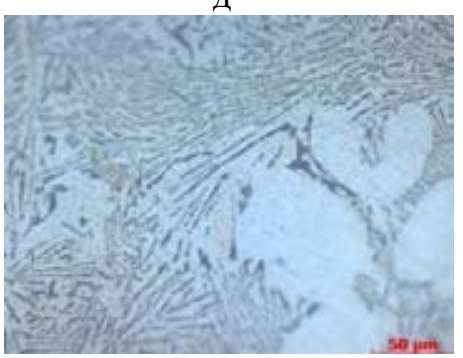

сплав 5

3

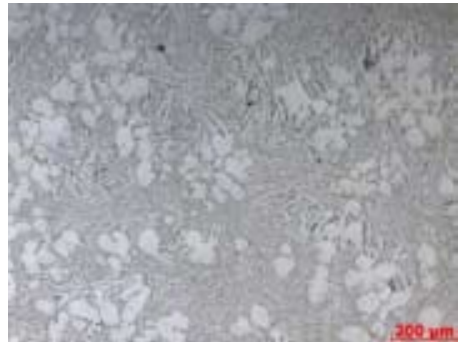

сплав 6

B

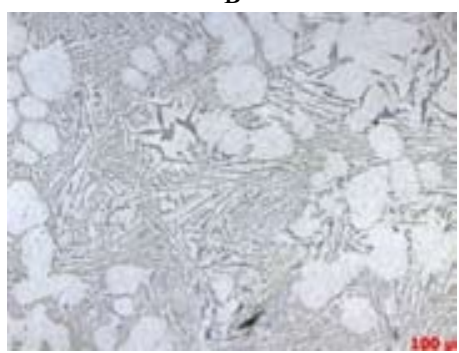

сплав 6

$\mathrm{e}$

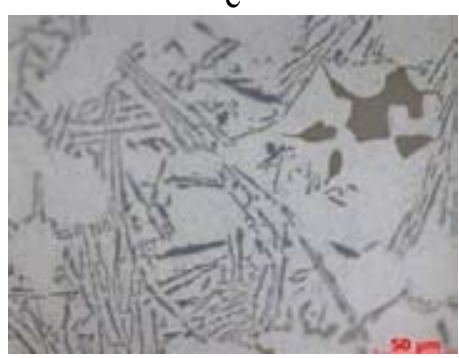

сплав 6

и

Рис. 2. Микроструктура опытных сплавов № 4 - 6: а, б, в -×100; г, д, е -×200; ж, 3, и - ×500

При сравнении прочностных свойств образцов из сплавов № 2 и 3 , представленных на рис. 3, видно, что доведение соотношения $\mathrm{Fe}: \mathrm{Mn}$ до $1: 1$ способствует увеличению механических свойств.

Опытные сплавы с соотношениями Fe : Mn, равными $1: 0,5$ (сплав № 2) и $1: 1$ (сплав № 3), были опробованы в заводских условиях ООО «КиК» при изготовлении дисков колес литьем под низким давлением.

Механические свойства были изучены на 30 дисках колес, объем выборки составил 300 образцов. Средние значения механических свойств образцов из трех зон колес показаны на рис. 4.

Увеличение твердости и прочности объясняется дополнительным упрочнением $\alpha$-твердого раствора алюминия марганцем. Значительный прирост твердости в зоне обода (внешней бортовой закраины) связан с тем, что в этой зоне наблюдается наибольшая объемная доля алюминиевой фазы.

Как показали металлографические исследования, изменение относительного удлинения объясняется условиями литья и кристаллизации фаз. Влияние грубой структуры на уро- 


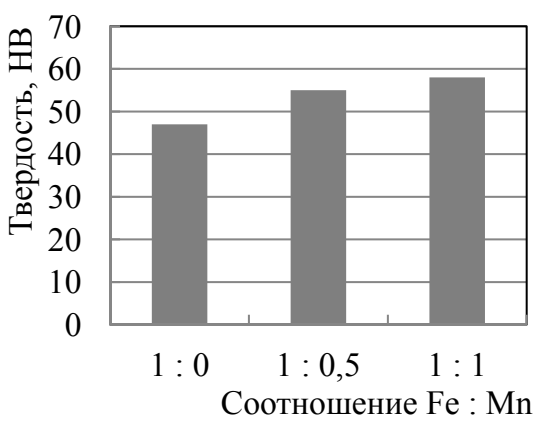

a

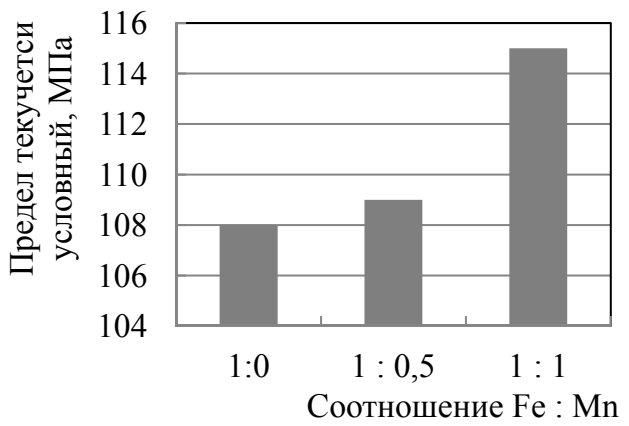

B

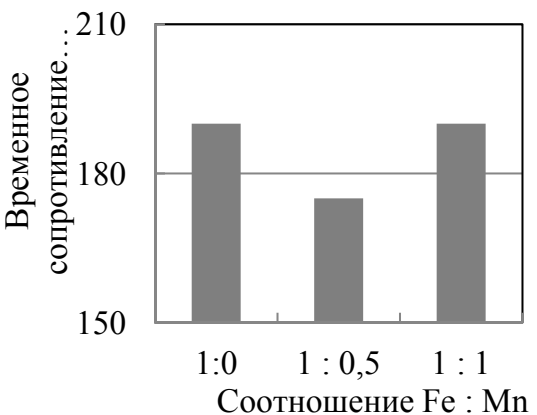

6

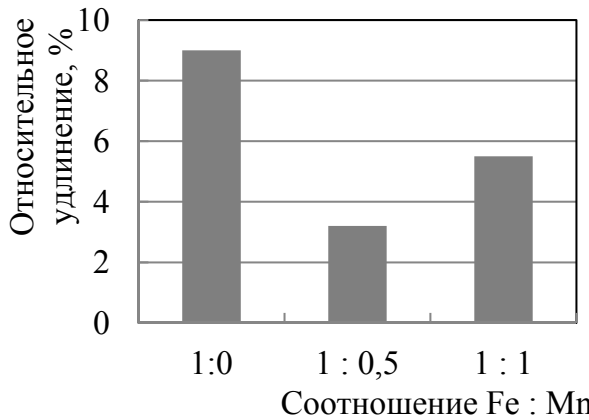

$\Gamma$

Рис. 3. Зависимость механических свойств опытных сплавов (сплав № 1-3) от соотношения в их составе Fe : Mn: a - твердость по Бринеллю; б - временное сопротивление разрыву, МПа; в - предел текучести условный; г- относительное удлинение

вень механических свойств спицы и ступицы нивелируется только в сплаве с соотношением $\mathrm{Fe}: \mathrm{Mn}=1: 1$. При этом происходит стойкое изменение морфологии $\beta$-фазы, что и дает повышение пластичности сплава.

При этом для образцов отливок из сплава с содержанием $\mathrm{Fe}: \mathrm{Mn}=1: 1$ значение стандартного отклонения ниже в два раза, чем для образцов для сплава с содержанием $\mathrm{Fe}: \mathrm{Mn}=1: 0,5$, что объясняется отсутствием грубых включений не модифицированной $\beta$-фазы, формированием более дисперсной гомогенной структуры. Кроме этого, 23 \% образцов отливок из сплава с содержанием $\mathrm{Fe}: \mathrm{Mn}=1: 0,5$ не соответствуют требованиям ГОСТ Р 50511-93 по удлинению, а 3,5 \% - по временному сопротивлению разрыву. Отклонений по механическим свойствам для образцов из сплава с соотношением $\mathrm{Fe}: \mathrm{Mn}=1: 1$ не наблюдалось.

Отрицательного влияния повышения содержания железа в сплаве на результаты стендовых испытаний колес по ГОСТ Р 50511-93 не установлено. Повышение прочности и твердости дало положительный результат при испытаниях стойкости колес удару под углом $13^{\circ}$, изготовленных из опытного сплава № 3 с соотношением $\mathrm{Fe}: \mathrm{Mn}=1: 1$.

Таким образом, при использовании сплава АК12 с повышенным содержанием железа при производстве колес литьем под низким давлением приоритетным является сохранение соотношения $\mathrm{Fe}: \mathrm{Mn}=1: 1$. 


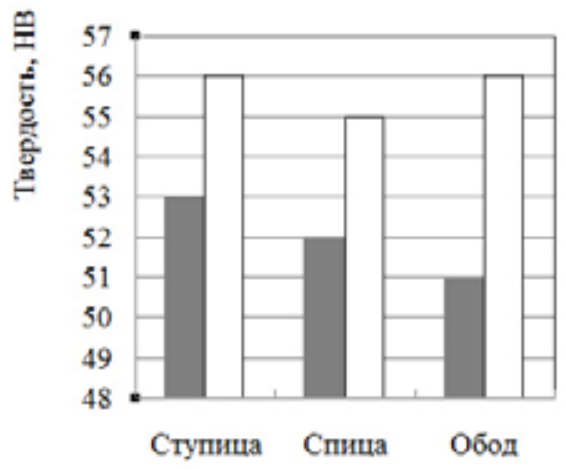

Зона колеса

a

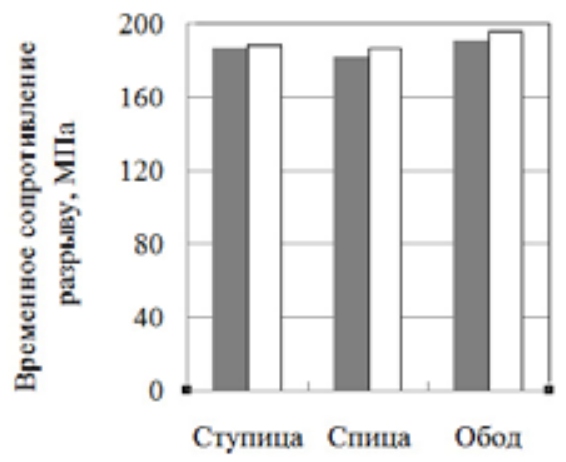

Зона колеса

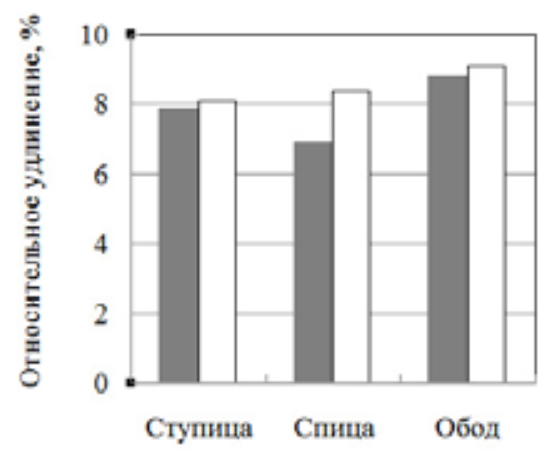

Зона колеса

6

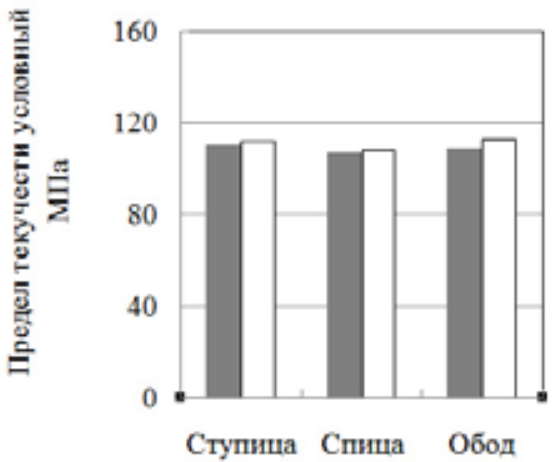

Зона колеса

B

$\Gamma$

Рис. 4. Зависимость механических свойств дисков колес, изготовленных из опытных сплавов № 2 и № 3 от соотношения в их составе $\mathrm{Fe}: \mathrm{Mn}: \mathrm{a}$ - твердость по Бринеллю; б - относительное удлинение; в - временное сопротивление разрыву; г - предел текучести условный. Соотношение $\mathrm{Fe}: \mathrm{Mn}: \boldsymbol{\square}-1: 0,5$ (сплав № 2); $\mathbf{\square}-1: 1$ (сплав № 3)

\section{Выводы}

1. При выплавке сплава АК12 использование первичного алюминия марки $\mathrm{A} 7$ вместо $\mathrm{A} 8$ для удешевления изделий возможно при введении элемента-компенсатора марганца. Установлено, что при литье автомобильных дисков под низким давлением содержание марганца в силумине не должно превышать 0,20-0,25 \% масс. при содержании железа 0,20-0,25 \% масс., т.е. соотношение $\mathrm{Fe}: \mathrm{Mn}$ должно быть равно $1: 1$. Получены механические свойства, удовлетворяющие требованиям ГОСТ 50511-93.

2. В исследуемом силумине при введении марганца не должно быть более $0,25 \% \mathrm{Fe}$, что вызывает огрубление структуры, причем доведение соотношения $\mathrm{Fe}: \mathrm{Mn}=1: 1$ в этом случае не приводит к улучшению структуры. 


\section{Список литературы}

[1] Богданова Т.А., Довженко Н.Н., Гильманшина Т.Р. и др. Литейное производство, 2015, 9, 5-8. [Bogdanova T.A., Dovzhenko N.N., Gilmanshina T.R. et al. Source of the Document Litejnoe Proizvodstvo, 2015, 9, 5-8 (in Russian)]

[2] Богданова Т.А. Разработка конкурентоспособной технологии литья автомобильных колес из силумина на основе алюминия А7. Автореф. дис. ... канд. техн. наук. Красноярск, 2015. 23 c. [Bogdanova T.A. The development of competitive technologies of casting of car wheels alluminium alloy based on aluminum A7. Krasnoyarsk, 2015, 23 p. (in Russian)]

[3] Новиков И.И., Строганов Г.Б., Новиков А.И. Металловедение, термообработка и рентгенография. М.: МИСиС, 1994. 480 с. [Novikov I.I., Stroganov G.B., Novikov A.I. Metallography, heat treatment and radiography. Moskow, MISIS, 1994. 480 p. (in Russian)]

[4] Золоторевский В.С., Белов Н.А. Металловедение литейных алюминиевых сплавов. М.: МИСиС, 2005, 375 c. [Zolotarevskii V.S., Belov N.A. Physical metallurgy of casting aluminium alloys. Moskow, MISIS, 2005, 375 p. (in Russian)]

[5] Белов В.Д., Белов Н.А. Металловедение и термическая обработка металлов. 2011, 9, 33-39 [Belov V.D., Belov N.A. Metallography and heat treatment of metals. 2011, 9, 33-39 (in Russian)] 